\title{
Developing measures of food and nutrition security within an Australian context
}

\author{
Claire Archer, Danielle Gallegos* and Rebecca McKechnie \\ School of Exercise and Nutrition Sciences, Queensland University of Technology, Victoria Park Road, Kelvin Grove, \\ QLD 4059, Australia
}

Submitted 28 February 2017: Final revision received 3 May 2017: Accepted 16 May 2017: First published online 31 July 2017

\begin{abstract}
Objective: To develop a measure of food and nutrition security for use among an Australian population that measures all pillars of food security and to establish its content validity.

Design: The study consisted of two phases. Phase 1 involved focus groups with experts working in the area of food security. Data were assessed using content analysis and results informed the development of a draft tool. Phase 2 consisted of a series of three online surveys using the Delphi technique. Findings from each survey were used to establish content validity and progressively modify the tool until consensus was reached for all items.

Setting: Australia.

Subjects: Phase 1 focus groups involved twenty-five experts working in the field of food security, who were attending the Dietitians Association of Australia National Conference, 2013. Phase 2 included twenty-five experts working in food security, who were recruited via email.

Results: Findings from Phase 1 supported the need for an Australian-specific tool and highlighted the failure of current tools to measure across all pillars of food security. Participants encouraged the inclusion of items to measure barriers to food acquisition and the previous single item to enable comparisons with previous data. Phase 2 findings informed the selection and modification of items for inclusion in the final tool.

Conclusions: The results led to the development of a draft tool to measure food and nutrition security, and supported its content validity. Further research is needed to validate the tool among the Australian population and to establish interand intra-rater reliability.
\end{abstract}

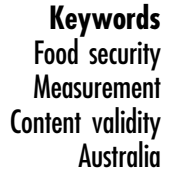

Australia
Food and nutrition security has been defined internationally and is considered a basic human right ${ }^{(1)}$. The accepted definition of food and nutrition security is that it 'exists when all people at all times have physical, social and economic access to food, which is safe and consumed in sufficient quantity and quality to meet their dietary needs and food preferences ... allowing for a healthy and active life ${ }^{,(2)}$. This definition is underpinned by a conceptual framework which identifies four pillars of food security: food access, availability, utilisation and stability ${ }^{(3)}$.

Food and nutrition insecurity may be associated with a range of adverse outcomes among adults and children. With limited food available in a household and limited financial resources to purchase food, individuals may resort to the consumption of cheap, poor-quality foods, high in energy, fat and sugar, and of low nutritional value $^{(4,5)}$. Among adults, food insecurity and the resultant dietary patterns have been associated with obesity, particularly among women ${ }^{(6)}$, an increased risk of chronic conditions including diabetes and hypertension ${ }^{(4,7)}$, as well as anxiety, depression and mood disorders ${ }^{(4,5)}$. Among children, food insecurity may be associated with poorer general health ${ }^{(8,9)}$, atypical or problematic behaviour $^{(4)}$ and issues with development during toddler years $^{(10)}$. Severe food insecurity can also lead to nutritional deficiencies $^{(11,12)}$ and inadequate energy intake ${ }^{(5)}$, resulting in weight loss and low body weight ${ }^{(4)}$. Given the potential adverse impacts of food insecurity on health, it is an issue of great concern that may be contributing to the growing national burden of disease.

Various single-item and multi-item tools have been developed to determine the prevalence of food insecurity at a population level. These measures are outlined in Table 1. In Australia, the measurement of food insecurity is limited to a single item from the Radimer/Cornell Food Security Scale, included in the three-yearly National Health 
Table 1 Reliability, sensitivity and specificity of tools for measuring household food security status ${ }^{(18)}$

\begin{tabular}{|c|c|c|c|}
\hline Measurement tool & $\begin{array}{c}\text { No. of } \\
\text { questions }\end{array}$ & $\begin{array}{c}\text { Reliability } \\
\text { (Cronbach's } a)\end{array}$ & $\begin{array}{l}\text { Sensitivity/ } \\
\text { specificity }\end{array}$ \\
\hline \multicolumn{4}{|l|}{ Single-item measures } \\
\hline $\begin{array}{l}\text { USDA Food Sufficiency } \\
\text { question }^{(18)}\end{array}$ & 1 & NR & $\begin{array}{l}\text { Sensitivity: } 32 \% \\
\text { Specificity: } 90 \%\end{array}$ \\
\hline $\begin{array}{l}\text { EFNEP Evaluating/ } \\
\text { Reporting System } \\
\text { question }^{(18)}\end{array}$ & 1 & NR & NA \\
\hline $\begin{array}{l}\text { Concern About Food } \\
\text { Security question }\end{array}$ & 1 & NR & NA \\
\hline $\begin{array}{l}\text { Single-item NHS } \\
\text { question }^{(15)}\end{array}$ & 1 & NR & $\begin{array}{l}\text { Sensitivity: } 57 \%{ }^{*} \\
\text { Specificity: } 96 \%{ }^{*}\end{array}$ \\
\hline \multicolumn{4}{|l|}{ Multi-item measures } \\
\hline CCHIP Hunger Index ${ }^{(18)}$ & 8 & $0.80-0.89$ & NA \\
\hline Radimer/Cornell FSS ${ }^{(18)}$ & 13 & $0.84-0.86$ & $\begin{array}{l}\text { Sensitivity: } 89 \% \\
\text { Specificity: } 63 \%\end{array}$ \\
\hline USDA HFSSM ${ }^{(18)}$ & 18 & $0.74-0.93$ & NA \\
\hline
\end{tabular}

USDA, US Department of Agriculture; EFNEP, Expanded Food and Nutrition Education Program; NHS, (Australian) National Health Survey; CCHIP, Community Childhood Hunger Identification Project; FSS, Food Security Scale; HFSSM, Household Food Security Survey Module; NR, not relevant. NA, not available.

Values for test-restest reliability not available for any tools.

*USDA HFSSM is the comparison tool.

Survey (NHS). This single item asks whether anyone in a household has run out of food in the preceding 12 months and been unable to purchase more due to a lack of money. Households that respond affirmatively to this question are followed up with a sub-question that asks: 'When this happened, did you or members of your household go without food? ${ }^{, 13)}$. Due to the presumed low prevalence of $5 \%$ among the general population, food insecurity data are not routinely collected in Australia. The latest survey to assess food insecurity in the Australian population was the Australian Health Survey in 2011-12. Prior to this, the last time food insecurity was assessed among the general population was in the 2004-05 NHS, having been omitted from the 2007-08 NHS $^{(14)}$. Previous studies have suggested that the single-item measure (used to estimate food insecurity in Australia) may underestimate the prevalence of food insecurity by approximately 5\% compared with more comprehensive multi-item measures ${ }^{(15)}$. While this item has been found to have a high level of specificity (96\%), it has a low sensitivity of only $57 \%{ }^{(15)}$, meaning that its accuracy in the identification of households experiencing food insecurity is poor. It also fails to consider diet quality, thereby ignoring nutrition as an important consideration for food and nutrition security. In addition, the Radimer/Cornell single item cannot distinguish between different levels of severity of food insecurity ${ }^{(16)}$, which range from concern about not having enough food to the most severe form, at which point children in the household are food insecure and experience hunger ${ }^{(17)}$. These limitations also apply to other single-item measures, including the Concern About Food Security question, the US Department of Agriculture Food Sufficiency question, and the Expanded Food and Nutrition Education Program Evaluating/Reporting System question $^{(18)}$.
Ideally, information on a variety of experiences and behaviours must be collected to accurately illustrate the varying degrees of severity of food insecurity. While data on sensitivity and specificity are not available for all measures of food security, as shown in Table 1, the data available suggest that greater sensitivity can be achieved through use of a multiitem tool compared with single-item tools. The high level of reliability seen for multi-item measures further supports their use in the measurement of food insecurity across different levels of severity. Although the comprehensive, multi-item tools provide more accurate measures of food security, distinguish between varying degrees of food insecurity, and may provide information on child and adult household food security status separately ${ }^{(19)}$, they have a number of limitations. These tools are not validated among the Australian population $^{(20)}$ and focus solely on a single domain of food insecurity (affordability). They fail to consider other factors contributing to food insecurity within an Australian context, such as issues with transport to food stores ${ }^{(21,22)}$, the availability of food in local stores, especially in remote areas ${ }^{(23)}$, and the availability of culturally appropriate foods ${ }^{(24)}$. In this way, these measures do not consider all four pillars of food security and may underestimate the prevalence of food insecurity among particular at-risk subgroups of the Australian population, such as those living in rural or remote areas ${ }^{(25,26)}$, migrants and refugees ${ }^{(24)}$, and older adults who are socially isolated $^{(27)}$. The public health significance of the implications of food insecurity warrants appropriate monitoring and surveillance of this issue, using an accurate and comprehensive tool, to allow for the development of appropriate, targeted interventions for its alleviation.

The present research aimed to develop a tool capable of measuring food and nutrition security across all four pillars of food insecurity among the Australian population and to evaluate its content validity.

\section{Methods}

\section{Study design}

The study consisted of two phases. Phase 1 involved focus groups with dietitians who were attending the Dietitians Association of Australia National Conference, 2013 and who had an interest in, or were working in, the area of food security. Data from this phase were analysed and used to develop a draft tool. Phase 2 consisted of a series of three online surveys (comprising both quantitative and qualitative questions) conducted using the Delphi technique, which enabled revision of the tool. Figure 1 provides a summary of the study methodology.

\section{Phase 1}

Participants and sample

Twenty-five dietitians with an interest in or working in the field of food security, who had registered to attend a food 

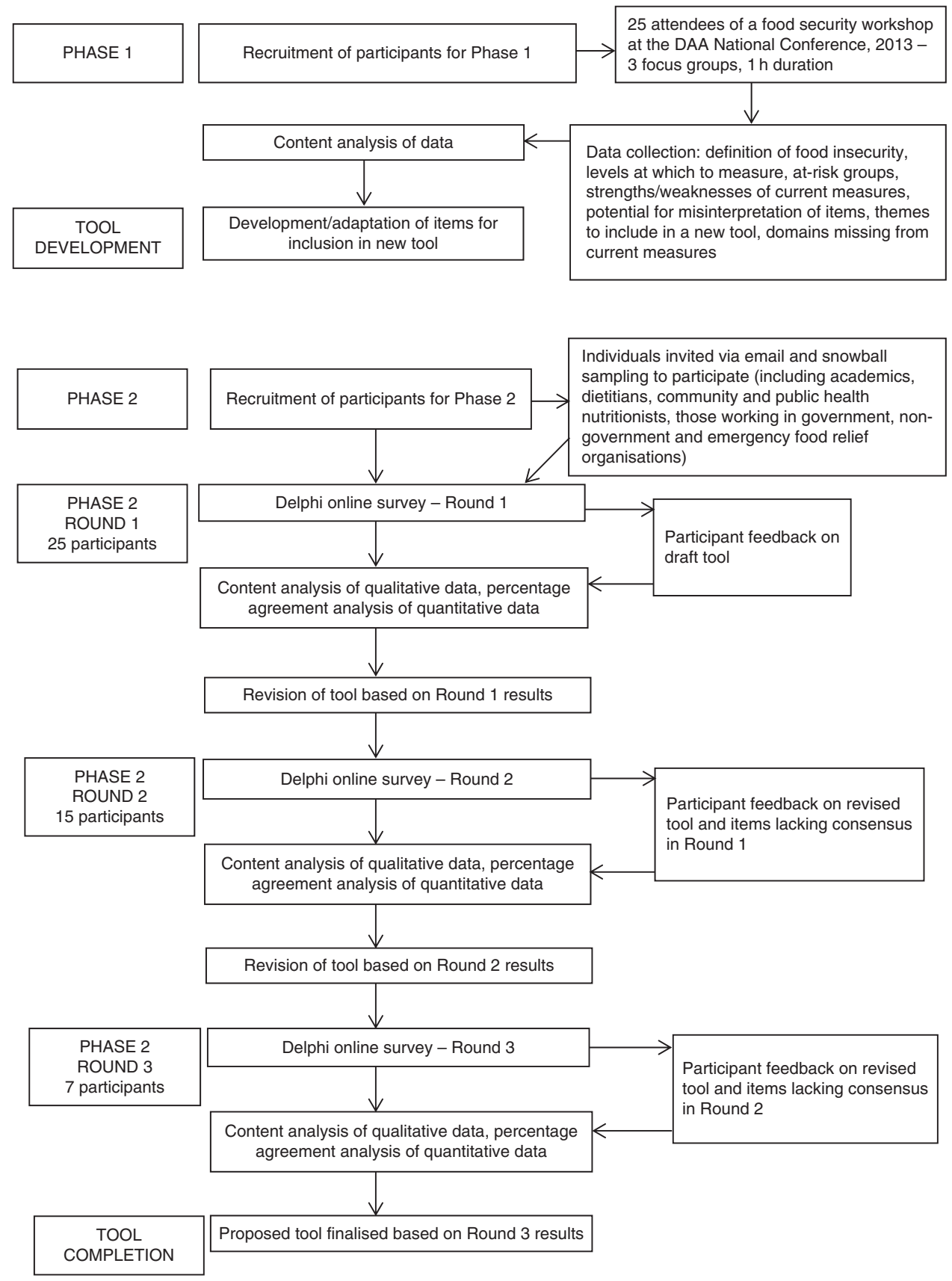

Fig. 1 Study design and methodology for development of an Australian food security measurement tool and content validation (DAA, Dietitians Association of Australia)

security workshop at the annual Dietitians Association of Australia conference, were invited to participate in focus groups to inform the development of an Australianspecific measure of food security. All workshop registrants received an email invitation to participate, along with a summary of existing measures of food security that are currently available and the focus group interview schedule. Participants worked across a range of areas of dietetics including community and public health, clinical acute care, research, and policy development.

\section{Data collection}

During the food security workshop, members of the research team facilitated three simultaneous focus groups of $1 \mathrm{~h}$ duration. The interview schedule consisted of ten open-ended questions, asking participants their opinions about the necessity to measure food security, at which level measurement should occur (household/individual, community, national), what groups would benefit from a specific measure of food security, what themes should be included in an Australian-specific measure of food 
security, whether there are any limitations with current measures and whether these current measures are fulfilling their intended purpose. Participants' responses were audio-recorded and transcribed.

\section{Data analysis}

Data were assessed via a content analysis, during which responses to questions were interpreted and systematically classified via coding into themes and patterns ${ }^{(28)}$. Wording used by participants was maintained to prevent the loss of meaning.

\section{Construction of the Australian food security tool}

Based on the themes identified, nine potential items for inclusion in the food security tool were compiled utilising components of existing measures of food security (US Department of Agriculture Household Food Security Survey Module, Radimer/Cornell Food Security Scale, New Zealand National Health Survey food security questions). Items were combined in ascending order of 'severity', ranging from the experience of anxiety or worry that food may run out, to adults or children skipping meals or going an entire day without eating due to an inability to acquire food. This draft tool took into consideration the focus group findings relating to the level at which food security should be measured, issues with current measures, themes that should be included and items missing from existing measures.

\section{Phase 2}

\section{Participants and sample}

Participants in the workshop who were willing to participate, as well as other experts who had been identified as working in the area of food security across Australia (including academics, those working in government and non-government organisations, staff of emergency food relief organisations, dietitians, and community and public health nutritionists), were invited via email to take part in a series of three online surveys. Snowball sampling was also utilised, with potential participants asked to forward the study link on to others working in the area of food security.

\section{Data collection}

Data were collected via three rounds of online surveys administered according to the Delphi technique. This methodology involves a group of experts on a given topic providing their opinions on the research problem over a series of rounds, with the ultimate goal being to reach a predetermined level of consensus. Questions are presented to the group repeatedly (i.e. the respondents from the first survey are the same for the second and third surveys) until this consensus is achieved or the Law of Diminishing Returns is evident ${ }^{(29-31)}$. In the present study, consensus initially required agreement among at least $75 \%$ of participants $^{(32-34)}$.
Surveys were developed using KeySurvey, an Internetbased survey system. For all individual items that made up the draft tool, each participant was asked to indicate which he/she thought should remain in the final version or which he/she thought should be excluded. Questions also asked whether any important items or concepts had been omitted and whether any items, or wording of items, could be interpreted in a way other than intended.

The draft tool was presented to participants for feedback through the online surveys described. As per the Delphi process, responses were collated and analysed to refine the draft version of the tool, after which a link to an adapted version of the previous survey was sent to participants. Items which reached $75 \%$ consensus for inclusion were retained in the final tool, whereas items which reached $75 \%$ consensus for exclusion were removed. The inherent nature of the Delphi process allows participants to reassess their initial judgements to subsequently modify previous comments or responses based on the ability to review and assess feedback in the context of comments from other Delphi respondents ${ }^{(35)}$. As such, when consensus was not achieved regarding inclusion or exclusion of an item (i.e. less than $75 \%$ agreement for a 'Yes' or 'No' response, respectively), the item was presented again to the group in the subsequent round, along with an explanation of why the question was being asked a second time.

\section{Data analysis}

Data for closed-ended quantitative questions were summarised as percentages, with $75 \%$ set as the requirement for consensus. Responses to open-ended qualitative questions requiring written feedback were assessed via a content analysis and frequency of response occurrence was used to identify the most common themes.

\section{Revisions and content evaluation of Australian food security tool}

The proposed tool was modified based on the feedback from survey respondents. As indicated above, items which reached a consensus of $75 \%$ or more for inclusion were retained in the final survey; items which reached a consensus of $75 \%$ or more for exclusion were removed. A small number of items did not reach consensus for either inclusion or exclusion; of these, those that $50 \%$ or more of the participants indicated should remain were retained, with the potential for exclusion based on future consultation with experts, vulnerable subgroups and pilot testing utilising rigorous quantitative methodologies to assess the psychometric properties of the tool and the contribution to measurement by each individual item. The retention of items that reach a consensus level of $51 \%$ in a required category is also consistent with previous practice $^{(36)}$. Suggestions made by participants for changes to wording and response categories were also incorporated in the revision of the tool. 


\section{Results}

\section{Focus groups - Phase 1}

Key themes that emerged from the focus groups indicated the following: there is a perceived need for a multi-item Australian-specific tool; the tool needs to measure beyond food affordability and be able to assess all of the underlying domains of food security; the severity of food insecurity must be able to be measured; the time frame for measurement may be problematic; and the tool should be generic with additional items added for particular groups if necessary.

\section{Need for a multi-item Australian-specific tool}

Participants suggested that the single-item tool currently utilised for the measurement of food security in Australia is inadequate alone. There exists a need for standardised measures of household, community and national food security that are Australian-specific and able to measure concepts across all pillars of food security. There was a particularly strong focus on measurement at the household and community levels. However, a large proportion of subsequent responses from participants focused on household-level food security. Despite the inadequacy of the current single-item measure, it was suggested that the one question be retained within a larger tool to enable comparisons with previous data:

'As a tool on its own, the one question is not enough.'

'Even if we are not happy with it, we have to have the one question as it has been used for 15 years, and gives some kind of consistency and tells a story over time.'

\section{Going beyond food affordability}

The current focus of existing tools on only one aspect of food security, affordability, was highlighted as a significant limitation to measurement, with issues of food access, availability and utilisation failing to be considered:

'In the ABS [Australian Bureau of Statistics] survey even very high income earners tick the run out of food category, so it's not just about total money it's about convenience, affordability, time, rent, household spending, and food becomes a discretionary item.'

To address this issue, it was suggested that any new tool assess multiple barriers to food security including transport, distance to food stores, geographic location, financial resources, housing, cooking and storage facilities, cooking skills, cost of healthy compared with unhealthy foods, food literacy and mobility issues:

'I find them all victim-centric, and there is a lack of consideration of barriers outside the home. Identifying barriers is important; maybe there could be a question "are any of these barriers to" ... It could be personal transport, public transport or both.'
'We are measuring someone's current food security status but we are not measuring some of the deeper determinants of food insecurity.'

'There is a lot of focus on affordability. Maybe this could be broadened in scope (e.g. "can I access food").'

'I think that identifying barriers is important to a rights-based approach to food, rather than focusing on individual accountability.'

'We need a tool that looks at domains other than just affordability (availability and access and any other number of domains).'

\section{Measuring severity}

Participants strongly encouraged the measurement of food insecurity among adults, adolescents and children, and suggested that any tool developed should seek to differentiate between the varying levels of severity of food insecurity, which the single item used previously failed to do:

'I think that we should try to measure the level of severity of food insecurity.'

'Children and young people are not asked enough about their experiences of food insecurity.'

'Whichever survey you choose you want one that gives you the most detail on populations.'

\section{Time frame and generic tool}

Participants also expressed a range of views regarding an appropriate time frame over which items in the tool should gather information and the complexities associated with determining a reference time frame for measurement. Some suggested that asking households about their food security status over the previous 12 months is too long a period, while others suggested that this be a minimum:

'It is difficult to shorten the time period due to the transience [of food insecurity].'

'You might ask in the last 12 months, but invariably people might think over the last two weeks.'

Lastly, focus group participants suggested that a single, generic tool be developed, with additional items of relevance to particular at-risk populations that could be added to the generic tool to make it more suitable for these subgroups:

'I would like to see a tool that is generic and applicable to everybody, rather than having a separate tool for each vulnerable group.'

'You might have a single central tool and maybe you can add a couple of questions and tailor that tool as you need to suit specific groups.' 


\section{Delphi study - Phase 2}

Due to the use of a snowball sampling technique, whereby potential participants were encouraged to forward the study link on to others working in the area of food security, the total number of people initially contacted is unknown and an initial response rate unable to be calculated. Twenty-five people participated in the first survey round. Of the initial twenty-five respondents, fifteen continued participation in the second round. Seven of the fifteen respondents from the second round then participated in the third round. This resulted in response rates of $68.2 \%$ and $31.8 \%$ for the second and third rounds, respectively.

\section{Round 1 survey}

Consensus was reached in Round 1 for twenty-four items/ sub-items in the draft tool. The remaining twenty-five items/sub-items that did not reach consensus were reassessed in the subsequent second round of surveys. Qualitative feedback from participants provided additional items and response options that could be included and ways in which the wording of items in the draft tool could be modified. A commonly occurring theme was that the subjective nature of the term 'quality food' and potential for misinterpretation may limit the validity of the item related to this component of food and nutrition security. Consequently, 'quality food' was replaced by 'safe food', reflecting a definition of quality that includes acceptable food that is safe to eat. 'Nutritious' was proposed by numerous respondents as a more suitable descriptor than 'healthy', which was identified as a value-laden term that could be confused with products marketed as 'health foods'.

Participants highlighted certain areas that the draft tool did not cover, suggesting specific response categories be added to the first question relating to access to, and availability of, culturally appropriate food; items were subsequently included and sent out for comment in the following rounds. With regard to wording, participants recommended that items and response options be simplified to improve readability and comprehension. Lastly, it was suggested that the 12-month time frame used in previous food security measures is too long. These recommendations were again taken into consideration in revision of the tool.

\section{Round 2 survey}

Participants did not support the inclusion of the item asking about access to 'safe food' in the final tool (53.3\% responded ' $N o$ '), with qualitative feedback indicating that this term may also be misunderstood by respondents and that 'safe' would need to be defined if this item were to be included. With regard to barriers to food security that had not received at least $75 \%$ agreement in Round 1, percentage agreement for inclusion in the final tool increased across the majority of response options in
Round 2. Agreement also increased for many of the specific adult-related and child-related items for which consensus was not achieved in the previous round. Those still not receiving $75 \%$ consensus asked whether adults in the household had eaten less than they thought they needed ( $73.3 \%$ answered 'Yes') and whether children had the size of their meals cut down over the given time period ( $53.3 \%$ answered 'Yes'). As discussed previously, items which did not receive $75 \%$ agreement for either inclusion or exclusion, but which at least $50 \%$ of participants thought should be included in the final tool, were retained for future investigation among a larger sample. The $50 \%$ agreement was considered adequate due to the dwindling number of respondents and the decision made to include these initially until further validation studies could assess their meaningful contribution to the measure.

The survey also asked participants whether the final tool should measure the frequency of experiences of food insecurity for all items, as responses from the previous round had been mixed (55\% responded 'Yes', 45\% responded ' $N o$ '). An increase was seen in support for measuring frequency for all items, with $64.3 \%$ answering affirmatively. As more than $50 \%$ supported this, revisions to the tool included response options measuring frequency for all items in the tool. Lastly, minor changes were again proposed to the wording of certain items and response options, and were taken into consideration in tool modification prior to the final round.

\section{Round 3 survey}

Items that did not reach the cut-off for consensus, but for which $50 \%$ or more of respondents indicated should be included, were retained in the draft tool assessed during Round 3. Participants agreed unanimously with this process, thus these items were retained in the final version of the tool. Findings from this final round of surveys supported the content validity of the tool developed. Respondents agreed that the tool reflected barriers to food acquisition (100\%) and experiences of food insecurity that evaluated the varying severities of the issue (100\%), and assessed concepts across the four pillars of food security ( $85.7 \%)$ and both food and nutrition security (85.7\%). The items included in the final version of the tool are summarised in Table 2.

\section{Discussion}

The themes identified from participant responses throughout the study assisted in addressing limitations of existing tools. Focus group participants suggested that a new tool should measure a broader range of barriers to food security, which would enable evaluation of the access, availability and utilisation pillars of food security, addressing a limitation identified in food security measures 
Table 2 Items reaching consensus for inclusion in the final Australian food security measurement tool

\begin{tabular}{|c|c|c|}
\hline Item & $\begin{array}{l}\text { Agreement on } \\
\text { inclusion in final tool (\%) }\end{array}$ & $\begin{array}{l}\text { Corresponding pillar } \\
\text { of food security }\end{array}$ \\
\hline \multicolumn{3}{|l|}{ Anyone else in house or home } \\
\hline Ever not had enough food to eat? & $79 \cdot 2$ & Access \\
\hline Ever not been able to have nutritious food to eat?* & $52 \cdot 2$ & Access \\
\hline \multicolumn{3}{|l|}{ Barriers to enough food, or nutritious food } \\
\hline There just isn't enough money for food & $100 \cdot 0$ & Access (affordability) \\
\hline There are too many other things to pay for (such as rent, bills, medicines, etc.) & $100 \cdot 0$ & Access (affordability) \\
\hline The food in the store, shops, supermarket or market costs too much & $92 \cdot 3$ & $\begin{array}{l}\text { Access (affordability) } \\
\text { Availability }\end{array}$ \\
\hline It is too hard to get to the store, shops, supermarket or market & $100 \cdot 0$ & Access \\
\hline The store, shops, supermarket or market is too far away* & 66.7 & Access \\
\hline The shops don't sell or stock nutritious food & $100 \cdot 0$ & Availability \\
\hline Food that is familiar or appropriate for our culture or religion is not available & $100 \cdot 0$ & Availability \\
\hline Don't know what food to buy & 78.6 & Utilisation \\
\hline Don't know how to prepare or cook food & $100 \cdot 0$ & Utilisation \\
\hline No place to store food safely & $100 \cdot 0$ & Utilisation \\
\hline Don't have the equipment to prepare or cook food & $100 \cdot 0$ & Utilisation \\
\hline Kitchen is not sufficient or safe for cooking* ${ }^{*}$ & 61.5 & Utilisation \\
\hline Not enough time to cook or shop & $100 \cdot 0$ & Utilisation \\
\hline Physical or mental health condition that stops me being able to cook or eat properly & 93.3 & Access/Utilisation \\
\hline \multicolumn{3}{|l|}{ Because of barriers above, have any adults in house/home } \\
\hline Ever felt worried or stressed that food will run out for any adults in your house/home? & $95 \cdot 8$ & $\dagger$ \\
\hline Ever felt worried or stressed that food will run out for any children in your house/home? & $100 \cdot 0$ & $\dagger$ \\
\hline $\begin{array}{l}\text { Felt stressed or left out because you couldn't provide food for special occasions } \\
\text { (e.g. being unable to invite people over for a meal or party)? }\end{array}$ & $86 \cdot 7$ & $\dagger$ \\
\hline Limited the variety of food you ate? & $85 \cdot 7$ & $\dagger$ \\
\hline Relied on others to provide food or money for food? & $91 \cdot 7$ & $\dagger$ \\
\hline Used emergency food relief or food banks? & 87.5 & $\dagger$ \\
\hline $\begin{array}{l}\text { Ever gone without food, or changed the types of food that you eat, to pay for } \\
\text { other expenses (e.g. bills)? }\end{array}$ & $87 \cdot 5$ & $\dagger$ \\
\hline Ever eaten less than you thought you needed?* & $73 \cdot 3$ & $\dagger$ \\
\hline Run out of food and not been able to get more? & 83.3 & $\dagger$ \\
\hline Ever gone hungry? & $75 \cdot 0$ & $\dagger$ \\
\hline Ever cut the size of your meals or skipped meals? & $78 \cdot 3$ & $\dagger$ \\
\hline Ever not eaten for a whole day? & 92.9 & $\dagger$ \\
\hline \multicolumn{3}{|l|}{ Because of barriers above, have children } \\
\hline Had a limited variety of food to eat? & $78 \cdot 6$ & $\dagger$ \\
\hline Been unable to eat nutritious meals? & $86 \cdot 7$ & $\dagger$ \\
\hline Ever relied on a school breakfast programme for food? & $75 \cdot 0$ & $\dagger$ \\
\hline Had to have smaller sized meals?* & $53 \cdot 3$ & $\dagger$ \\
\hline Not been able to eat as much food as you thought they needed? & $85 \cdot 7$ & $\dagger$ \\
\hline Ever gone hungry? & $83 \cdot 3$ & $\dagger$ \\
\hline Skipped meals? & $85 \cdot 7$ & $\dagger$ \\
\hline Ever not eaten for a whole day? & $100 \cdot 0$ & $\dagger$ \\
\hline Able to afford or access fruits and vegetables to eat on most days? & $85 \cdot 7$ & Access \\
\hline In the last 12 months ran out of food and couldn't afford to buy more & $83 \cdot 3$ & Access \\
\hline
\end{tabular}

${ }^{*}$ Item did not reach $75 \%$ consensus for inclusion or exclusion, but reached at least $50 \%$ agreement for inclusion, and was retained for further assessment in future validation studies.

†Question could assess access, availability or utilisation depending on barriers selected by participant in previous item.

currently available that often focus solely on food insecurity resulting from financial constraints. Further supporting this is research by Saunders et $a l .^{(37,38)}$ on measures of deprivation, which suggests that a focus on poverty status alone does not acknowledge other factors beyond financial resources that can contribute to household deprivation. Addressing limitations of existing food security tools will provide additional information not gathered previously and offer avenues for interventions to address food insecurity more effectively within population groups.

The diverse nature of the Australian population creates difficulties in constructing a single tool to be used among the general population and specific sub-populations alike.
As such, the suggestion for a generic tool with additional questions of relevance to specific subgroups that can be added would assist in making the tool applicable to various at-risk groups within the population. Consultation with food security experts working with such groups would assist in ensuring the tool is tailored to be as applicable and relevant as possible to these groups and their experiences of food insecurity. Future consultation with experts, vulnerable subgroups and traditional validation studies will also assist in refining response categories for measuring frequency and further investigating items that were retained in the current study, despite not reaching the ideal $75 \%$ consensus cut-off. 
With regard to the suggestion from survey respondents to use a time frame shorter than 12 months in items in the tool, this is supported by research suggesting that specifying a 12-month period does not necessarily provide an accurate indication of household food security status at the given point in time, due to the significant changes that can occur within a household over 12 months ${ }^{(39)}$. From this comment and the varied time frames proposed during Phase 1 focus groups, it was decided that the tool would not specify a time frame but could instead be adapted to suit the particular context in which it is used. The exception to this is the single item previously included in the NHS, which was retained in the draft tool for consistency and which would need to maintain the 12-month time frame to ensure comparability with past data. Respondents' suggestion that the term 'nutritious' be used throughout the tool, rather than 'healthy', is also supported by literature, with other studies suggesting that the health value of foods can be interpreted differently by individuals, which makes 'healthy' a highly subjective term $^{(40,41)}$. Also stemming from respondent feedback, as an inability to access culturally appropriate food is a risk factor for food insecurity ${ }^{(24)}$, this potential barrier was added to the final version of the proposed tool.

Increases seen throughout the online surveys in consensus for inclusion of items may reflect the changes made to the wording and simplicity of response options, and the inclusion of additional options, based on participant feedback from previous rounds. The number of suggested changes to the wording of items also decreased considerably across the survey rounds, which is consistent with the Law of Diminishing Returns and reflective of movement towards consensus ${ }^{(31)}$. A failure to measure barriers to food acquisition, levels of severity of food insecurity and all four pillars of food security were highlighted as key weaknesses in tools currently available. As such, the proposed tool appears to address significant gaps in existing measures, with survey respondents indicating that the tool adequately covers these domains.

\section{Limitations}

The present study, and the tool that has been developed based on these results, should be considered within the context of certain limitations. In Phase 1 , the convenience sampling used is one aspect of the methodology with the potential to introduce bias, thereby preventing the findings from being generalisable across all individuals with expertise in food security. Due to the qualitative nature of the data obtained from the focus groups, interpretation of participants' comments and the resulting content analysis of these data could also be viewed as subjective. This presents another potential limitation of this phase of the study, as misinterpretation of comments could have resulted in themes being incorrectly identified during content analysis, thus misinforming the development of the draft tool.
Certain limitations of the study are also inherent in the Delphi technique employed in Phase 2. The sampling method is, again, one such area in which issues may arise in Delphi-based research. To gather opinions on a particular topic, individuals with expertise in the field must be consulted $^{(30)}$. However, this purposeful selection of individuals can produce a degree of bias ${ }^{(42)}$. With regard to sample size, the small number of participants may appear a limitation of the current study. However, when considering that larger sample sizes can produce saturation of responses prematurely, for the purpose of conducting research using the Delphi technique, a smaller sample size may be beneficial ${ }^{(43)}$. It has also been suggested that the Delphi technique may produce a consensus that does not reflect participants' true views, as some may be influenced to change their opinions upon observing results from the previous round if it is shown that a majority of the group supports an opinion different from their own ${ }^{(29-31,42)}$. Another potential issue is that unnecessary burden can be placed on respondents if required to answer the same question in successive rounds in order for consensus to be achieved $^{(44)}$. Delphi research can also be time-consuming and extended periods between rounds may result in participants losing interest and withdrawing their participation $^{(29)}$, which was observed in the current study. These characteristics of the Delphi technique pose a risk to continued participation of respondents and attrition can be an issue with studies utilising this method, which may contribute to response bias ${ }^{(32)}$. Strategies to reduce the risk of non-response include conducting the first round using a face-to-face interview approach ${ }^{(42)}$, as this may encourage the development of rapport and a stronger feeling of involvement and ownership of the research among participants $^{(32)}$. An Internet-based survey method also enables faster data collection and analysis, reducing time between rounds ${ }^{(29)}$. Both of these strategies were utilised in the present study. In addition, to reduce the burden on participants, efforts were made to keep surveys to a reasonable length and avoid repeating questions unnecessarily. Despite these strategies, given the declining response rates to the online surveys, the likelihood of response bias within the study is high, meaning that the opinions expressed by those participating in the surveys may not be representative of all experts in the field of food security ${ }^{(45)}$.

\section{Recommendations for future research}

Through the Delphi technique, the content validity of the proposed measure was assessed. The next stages of tool development will require further validation and pilot testing, establishment of a scoring protocol, and assessment of inter- and intra-rater reliability ${ }^{(46)}$. In conducting validation studies, the tool should be validated across all intended administration methods, including selfadministered (both paper-based and online formats) as well as interviewer-administered (face-to-face as well as 
telephone-based surveys). Tool validation is a complex process, comprising multiple types of validation and approaches to their investigation. Of note is the importance of a tool to be shown to be valid and reliable within specific groups in which it is used; for this reason additional research investigating the above modes of administration could also be conducted on the use of this tool within specific subgroups of the Australian population at particular risk of food insecurity, such as Indigenous Australians, culturally and linguistically diverse groups, lower-income households, older adults and individuals experiencing homelessness. As suggested in the focus groups, additional items could be devised to tailor the tool to these subgroups and the validity of the tool with the addition of these items could then be tested.

Future validation studies should seek to confirm the construct validity of the proposed tool by assessing its psychometric properties, as well as the contribution to the overall measurement of food security by each individual item, using appropriate methods. Of note will be the difficulty in identifying an appropriate comparison tool with which to confirm the criterion validity of the tool. Direct comparisons between this tool and other existing tools may prove difficult, as the majority of previous tools available focus solely on financial access as a barrier to food acquisition ${ }^{(47)}$ and as such assess a very different food security concept. However, it is still advisable that future studies seek to compare this proposed tool with other measures of food security, namely the US Department of Agriculture Household Food Security Survey Module, which is the most widely used measurement tool. To further overcome difficulties in confirming criterion validity, future validation studies could also assess the convergent validity of the tool by comparing with factors known to be associated with food insecurity, including demographic characteristics such as low income and household structure, and/or potential outcomes such as poor self-rated health, depression and dietary intakes.

Lastly, with strong support demonstrated from participants for the measurement of food security at the community level, future research should also work towards the development of a tool for measuring community food security, or the adaptation of existing community tools, for an Australian population. This would assist in more effectively capturing the stability pillar of food security, which is difficult to fully evaluate through a household food security measure as it relates more closely to the food supply at a community level. Together with the household food security tool, this would provide a toolkit for measuring food and nutrition security across both levels within an Australian context.

\section{Conclusions}

The measures of food security currently available do not provide an accurate representation of the true prevalence of food insecurity within Australia, have not been validated in an Australian context, and fail to consider the concept of nutrition security and all four pillars of food security. The present study provides the foundation for the development of an Australian-specific measure of food and nutrition security. With further validation, this tool could provide a more comprehensive, accurate estimate of the prevalence of food and nutrition insecurity within Australia and the contributing factors, thus enabling more targeted approaches to addressing this issue.

\section{Acknowledgements}

Acknowledgements: The authors would like to extend their sincere thanks to research assistant, Brooke Searle, for her contribution to the project, and to all who provided their expertise and valued input in the development of the tool. They would also like to acknowledge Helen Vidgen who provided feedback on an earlier draft of this paper. Financial support: This research received no specific grant from any funding agency in the public, commercial or notfor-profit sectors. Conflict of interest: None. Authorship: R.M. and D.G. conceptualised the research; R.M. and D.G. collected the data for the focus groups; R.M. and C.A. collected the Delphi data; C.A. and R.M. analysed all the data; C.A. wrote the draft manuscript; C.A., R.M. and D.G. all reviewed the manuscript. Ethics of human subject participation: This study was conducted according to the guidelines laid down in the Declaration of Helsinki and all procedures involving human subjects/patients were approved by the Queensland University of Technology Human Research Ethics Committee. Written informed consent was obtained from all subjects/patients.

\section{References}

1. United Nations (1948) The Universal Declaration of Human Rights. http://www.un.org/en/documents/udhr/ (accessed April 2013).

2. Committee on World Food Security (2012) Coming to Terms with Terminology: Food Security, Nutrition Security, Food Security and Nutrition, Food and Nutrition Security. Proceedings of the 39th Session of the Committee on World Food Security, Rome, Italy, 15-20 October 2012. Rome: FAO.

3. Food and Agricultural Organization of the United Nations (2009) Declaration of the World Summit on Food Security. Proceedings of the World Summit on Food Security, Rome, 16-18 November 2009. Rome: FAO.

4. Hadley C \& Crooks DL (2012) Coping and the biosocial consequences of food insecurity in the 21st Century. Am J Phys Anthropol 149, 72-94.

5. Seligman HK, Bindman AB, Vittinghoff E et al. (2007) Food insecurity is associated with diabetes mellitus: results from the National Health Examination and Nutrition Examination Survey (NHANES) 1999-2002. J Gen Intern Med 22, 1018-1023.

6. Martin MA \& Lippert AM (2012) Feeding her children, but risking her health: the intersection of gender, household food insecurity and obesity. Soc Sci Med 74, 1754-1764. 
7. Seligman HK, Laraia BA \& Kushel MB (2010) Food insecurity is associated with chronic disease among low-income NHANES participants. J Nutr 140, 304-310.

8. Cook JT, Frank DA, Levenson SM et al. (2006) Child food insecurity increases risks posed by household food insecurity to young children's health. J Nutr 136, 1073-1076.

9. Gundersen C \& Kreider B (2009) Bounding the effects of food insecurity on children's health outcomes. I Health Econ 28, 971-983.

10. Hernandez DC \& Jacknowitz A (2009) Transient, but not persistent, adult food insecurity influences toddler development. J Nutr 139, 1517-1524.

11. Eicher-Miller HA, Mason AC, Weaver CM et al. (2009) Food insecurity is associated with iron deficiency anemia in US adolescents. Am J Clin Nutr 90, 1358-1371.

12. Kirkpatrick SI \& Tarasuk V (2008) Food insecurity is associated with nutrient inadequacies among Canadian adults and adolescents. J Nutr 138, 604-612.

13. Australian Bureau of Statistics (2009) 4364.0 - National Health Survey: Summary of Results, 2007-2008 (Reissue). Canberra: ABS; available at http://www.abs.gov.au/ AUSSTATS/abs@.nsf/DetailsPage/4364.02007-2008\%20 (Reissue)?OpenDocument

14. Australian Bureau of Statistics (2010) National Nutrition and Physical Activity Survey 2011-12: Questionnaire. Canberra: ABS; available at http://www.ausstats.abs.gov.au/ ausstats/subscriber.nsf/0/734DF823586D5AD9CA257B8E00 14A387/\$File/national\%20nutrition\%20and\%20physical\%20 activity\%20survey\%202011-12\%20questionnaire.pdf

15. Nolan M, Rikard-Bell G, Mohsin M et al. (2006) Food insecurity in three socially disadvantaged localities in Sydney, Australia. Health Promot J Aust 17, 247-254.

16. Burns CA (2004) Review of the Literature Describing the Link Between Poverty, Food Insecurity and Obesity with Specific Reference to Australia. Carlton, Victoria: VicHealth.

17. Kendall A, Olsen CM \& Frongillo EA (1995) Validation of the Radimer/Cornell measures of hunger and food insecurity. J Nutr 125, 2793-2801.

18. Keenan DP, Olson C, Hersey JC et al. (2001) Measures of food insecurity/security. J Nutr Educ 33, 49-58.

19. Gulliford MC, Nunes C \& Rocke B (2006) The 18 Household Food Security Survey items provide valid food security classifications for adults and children in the Caribbean. $B M C$ Public Health 6, 26.

20. Temple JB (2008) Severe and moderate forms of food insecurity in Australia: are they distinguishable? Aust J Soc Issues 43, 649-668.

21. Burns CM \& Inglis AD (2007) Measuring food access in Melbourne: access to healthy and fast foods by car, bus and foot in an urban municipality in Melbourne. Health Place 13, 877-885.

22. Coveney J \& O'Dwyer LA (2009) Effects of mobility and location on food access. Health Place 15, 45-55.

23. Scelza BA (2012) Food scarcity, not economic constraint limits consumption in a rural Aboriginal community. Aust J Rural Health 20, 108-112.

24. Gallegos D, Ellies P \& Wright J (2008) Still there's no food! Food insecurity in a refugee population in Perth, Western Australia. Nutr Diet 65, 78-83.

25. Palermo CE, Walker KZ, Hill P et al. (2008) The cost of healthy food in rural Victoria. Rural Remote Health 8 , 1074-1082.
26. Ward PR, Coveney J, Verity F et al. (2012) Cost and affordability of healthy food in rural South Australia. Rural Remote Health 12, 1938-1947.

27. Quine S \& Morrell S (2005) Food insecurity in communitydwelling older Australians. Public Health Nutr 9, 219-224.

28. Hsieh H-F \& Shannon SE (2005) Three approaches to qualitative content analysis. Qual Health Res 15, 1277-1288.

29. Cole ZD, Donohoe HM \& Stellefson ML (2013) Internetbased Delphi research: case based discussion. Environ Manage 51, 511-523.

30. de Meyrick J (2003) The Delphi method and health research. Health Educ 103, 7-16.

31. Hasson F, Keeney S \& McKenna H (2000) Research guidelines for the Delphi survey technique. J Adv Nurs 32, 1008-1015.

32. Keeney S, Hasson F \& McKenna H (2006) Consulting the oracle: ten lessons from using the Delphi technique in nursing research. J Adv Nurs 53, 205-212.

33. Löfmark A \& Thorell-Ekstrand I (2004) An assessment form for clinical nursing education: a Delphi study. J Adv Nurs 48, 291-298.

34. Miró J, Huguet A \& Nieto R (2007) Predictive factors of chronic pediatric pain and disability: a Delphi poll. J Pain $\mathbf{8}$, 774-792.

35. Hsu C \& Sandford B (2007) The Delphi technique: making sense of consensus. Pract Assess Res Eval 12, issue 10, 1-8.

36. Giannarou L \& Zervos E (2014) Using Delphi technique to build consensus in practice. Int J Bus Sci Appl Manage 9, 66-82.

37. Saunders P, Naidoo Y \& Griffiths M (2008) Towards new indicators of disadvantage: deprivation and social exclusion in Australia. Aust J Soc Issues 43, 175-194.

38. Saunders P \& Naidoo Y (2009) Poverty, deprivation and consistent poverty. Econ Rec 85, 417-432.

39. Ohls J, Radbill L \& Schirm A (2001) Housebold Food Security in the United States, 1995-1997: Technical Issues and Statistical Report. Alexandria, VA: US Department of Agriculture.

40. Bisogni CA, Jastran M, Seligson M et al. (2012) How people interpret healthy eating: contributions of qualitative research. J Nutr Educ Behav 44, 282-301.

41. Ronteltap A, Sijtsema SJ, Dagevos H et al. (2012) Construal levels of healthy eating. Exploring consumers' interpretation of health in the food context. Appetite 59, 333-340.

42. Keeney S, Hasson F \& McKenna HP (2001) A critical review of the Delphi technique as a research methodology for nursing. Int J Nurs Stud 38, 195-200.

43. Holey EA, Feeley JL, Dixon J et al. (2007) An exploration of the use of simple statistics to measure consensus and stability in Delphi studies. BMC Med Res Methodol 7, 52 .

44. Landeta J (2006) Current validity of the Delphi method in social sciences. Technol Forecast Soc 73, 467-482.

45. Draugalis JLR \& Cecilia MP (2009) Best practices for survey research reports revisited: implications of target population, probability sampling, and response rate. Am J Pharm Educ 73, 142-144.

46. Streiner DL \& Norman GR (2008) Health Measurement Scales: A Practical Guide to Their Development and Use, 4th ed. Oxford: Oxford University Press.

47. Ashby S, Kleve S, McKechnie R et al. (2016) Measurement of the dimensions of food insecurity in developed countries: a systematic literature review. Public Health Nutr 19, 2887-2896. 